Weizmann Institute of Science in Rehovot, Israel, and their colleagues used cameras to track the locations of groups of four mice in an arena at night by painting their fur with fluorescent colours.

Models that assumed the mice act as individuals or interact in pairs (the typical model of mouse sociality) did poorly at describing the group's movement as a whole. Only models with interactions between three mice gave good approximations of the observed behaviour.

Using this model, the

$\sum^{\infty}$ researchers found that mice raised in standard lab environments were less individualistic than those who had lived in larger groups and in more complex enclosures.

eLife 2, e00759 (2013)

CLIMATOLOGY

\section{Geoengineering has its limits}

Blocking solar radiation cannot restore a high-carbon world to its preindustrial climate.

Ben Kravitz of the Pacific Northwest National Laboratory in Richland, Washington, and his colleagues analysed results from 12 climate models simulating quadrupled atmospheric carbon dioxide levels, and a matching reduction in solar radiation.

Blocking the sunlight kept average global temperatures in check while preventing 97\% of Arctic sea-ice loss, but the effects on temperature and precipitation varied by region, with the Arctic experiencing more warming and the tropics more cooling, as well as less rainfall in places.

The authors suggest that solar geoengineering cannot simultaneously correct for global and regional impacts from rising greenhouse-gas levels.

J. Geophys. Res. http://doi. org/nmz (2013)

\section{Protecting neurons from Parkinson's}

An enzyme that adds a phosphate group to a protein called $\alpha$-synuclein - the phosphorylated form of which tangles up inside neurons in Parkinson's disease - also targets the protein for destruction.

Hilal Lashuel and his colleagues from the Swiss Federal Institute of Technology in Lausanne injected rat brains with the genes for both $\alpha$-synuclein and the enzyme PLK2.

When they increased amounts of $\alpha$-synuclein, the rats lost specific neurons and developed Parkinsonlike symptoms. But both effects were avoided, and levels of neuronal $\alpha$-synuclein fell, when they overexpressed the gene for PLK2 at the same time.

They showed that the PLK2 enzyme protects neurons from $a$-synuclein toxicity by shepherding the protein into autophagy, a cellular process for clearing debris.

Proc. Natl Acad. Sci. USA http://doi.org/ $\mathrm{nmx}$ (2013)

$$
\text { ANIMAL BEHAVIOUR }
$$

\section{Puppeteer squid haunts the deep}

The deep-sea squid Grimalditeuthis bonplandi (pictured) uses its tentacles to mimic smaller sea creatures, attracting prey.

The animal's tentacle stalks are fragile in comparison to those of most squid, and its tentacle tips lack the suckers or hooks that are usually used to catch and manipulate prey.

Henk-Jan Hoving, then at the Monterey Bay Aquarium Research Institute in Moss Landing, California, and his colleagues analysed videos of seven G. bonplandi recorded by remotely operated submarines, the first observations ever made

COMMUNITY CHOICE

The most viewed papers in science
MARINE MICROBIOLOGY

\section{Marine plastic fantastic for microbes}

A new ecosystem is emerging on plastic marine debris in the world's oceans: the 'plastisphere'.

Tracy Mincer at the Woods Hole Oceanographic Institution and Linda Amaral-Zettler of the Marine Biological Laboratory in Woods Hole, both in Massachusetts, and their colleague sequenced the microbial communities on plastic litter floating in the sea. They revealed a complex food web living in biofilms on two types of plastic, made up of microbes that were genetically distinct from those in the surrounding seawater. Unlike those in seawater samples, the communities on plastic had an even spread of diversity and were not dominated by just one or two types.

Environ. Sci. Technol. http://doi.org/m4q (2013) of the squid in its natural habitat. The creatures moved their tentacles in a manner that resembled the movements of smaller animals such as fish or other cephalopods.

The researchers suggest that the motions cause vibrations, water movements or bioluminescence in nearby microorganisms. The squid then consume curious creatures that come to investigate.

Proc. R. Soc. B 280,

20131463 (2013)

For a longer story on this research, see go.nature.com/ byyusm

\section{by \\ GENETICS \\ A library of human knockouts}

The functions of all 20,000

human protein-coding genes are still not known, partly because large gene-knockout libraries are not available for human cells.

One strategy for making such a library is to use a retroviral gene trap that disrupts gene expression when inserted into different genes.
But this does not work for human cells, which have two copies of most genes. Now a team led by four researchers — Tilmann Bürckstümmer of biotech firm Haplogen in Vienna, Austria, and Thijn Brummelkamp, Giulio Superti-Furga and Sebastian Nijman of the Research Center for Molecular Medicine of the Austrian Academy of Sciences in Vienna - has overcome this problem.

The team used a cancer-cell line that has only one copy of most genes (near-haploid) to assemble a knockout library of 3,396 human genes. The collection should enable screens of a range of phenotypes, the team reports. Nature Meth. http://doi.org/ nmw (2013)

\section{CORRECTION}

The Research Highlight 'Soil life predicts nutrient flow' (Nature 500, 380; 2013) stated an incorrect affiliation. Franciska de Vries is now at the University of Manchester, UK.

\section{ONATURE.COM}

For the latest research published by Naturevisit:

www.nature.com/latestresearch 